\title{
Social Class and International Migration: Female Migrants' Narratives of Social Mobility and Social Status
}

\author{
Maja Cederberg \\ Oxford Brookes University
}

\begin{abstract}
It is well established that international migration involves not only geographical but also social mobility, as migrants achieve an improved socioeconomic position through increased economic opportunities, or experience downwards mobility as a result of not being able to transfer their economic, social or educational resources to the receiving country context. While the social mobility that accompanies migration is often considered in the migration literature, the implications for migrants' social class positioning has been less of a focus. This paper addresses this gap by looking at how female migrants in the UK evaluate social class trajectories as part of their biographical narratives. The paper brings wider sociological debates about class into a discussion about female migrants' socioeconomic trajectories and social status. By considering material as well as symbolic aspects of class divisions along with the transnational context in which migrants are embedded, the paper highlights the complexity of how migrants are positioned in class terms. It also looks at how class is subjectively interpreted, and outlines different ways in which migrants evaluate their class trajectories, for instance by conceiving of migration from a long-term perspective and in the context of the family unit, by emphasising different quality-oflife aspects, and by challenging dominant meanings associated with class hierarchies. The paper emphasises the intersection of class and gender in female migrants' experiences, and argues that subjective accounts of class provide an excellent opportunity to explore the complexity of how class is experienced in the context of international migration.
\end{abstract}

\section{Key words}

Gender; International migration; Migrant integration; Social class; Social mobility 


\section{Introduction}

It is well established that international migration involves not only geographical but also social mobility, as migrants achieve an improved socioeconomic position through increased economic opportunities, or experience downwards mobility as a result of not being able to transfer their economic, social or educational resources to the receiving country context. However, while the social mobility that accompanies migration is often considered in the migration literature, the implications for migrants' social class positioning has been less of a focus. Considering migrants' class trajectories in detail often reveals a complex picture, as they may simultaneously experience an improved economic position and a decline in social status. In her work on migrant domestic workers, Parrenas $(2000,2015)$ uses the term 'contradictory class mobility' to refer to the trajectories of female migrants who have achieved a higher income through domestic work in Western countries, but experience downwards social mobility by doing work holding a low social status (while often being highly educated). Furthermore, following the transnational turn in migration studies, we know that migration processes cannot be fully understood without attending to migrants' connections to multiple locations, and the series of links (economic, social, cultural and political) they often maintain (Glick-Schiller et al. 1992, Portes et al. 1999). As such, when studying social class processes across national boundaries, we need to consider the extent to which migrants are simultaneously embedded in different country contexts in which they may be differently positioned (Kelly 2012, Kelly and Lusis 2006, Nowicka 2013, Parrenas 2000, 2015).

This paper explores how social class transforms and is experienced in the context of international migration by considering how female migrants in the UK narrate classrelated processes as part of their biographical accounts. It looks at a number of ways in which class features in the women's lives and stories, considering different dimensions of class and how the women evaluate their socioeconomic trajectories, along with changes to their social status, through migration. The broad definition of class used in the paper is captured in the following quote from Bradley (2014: 432): '[c]lass is a social category which refers to lived relations surrounding social arrangements of production, exchange, distribution and consumption. While these 
may be narrowly conceived as economic relationships ... class should be seen as referring to a much broader web of social relationships, including, for example, lifestyle, educational experience and patterns of residence'. Furthermore, the status associated with those relationships, and the positions involved, also form important aspects of class relations, as socioeconomic divisions are reproduced symbolically as well as economically.

The paper draws on biographical interviews undertaken as part of a cross-national research project exploring the labour market and social integration of female migrants in different European countries (Anthias et al. 2013, Kontos et al. 2009). The sample is composed of 22 biographical interviews, and it was designed to reflect the patterns of female migrants' participation in the UK labour market. It includes women of different migrant categories, from different countries, and with different educational and employment profiles: a diverse sample that provides a useful basis for exploring the different ways in which social class is experienced and evaluated. At the same time, such diversity requires careful consideration of the multiple factors that shape the experience of migration. While some women have migrated for work or to study, others were forced to leave their countries of origin due to conflict or the risk of persecution, while yet others migrated for family-related reasons (although it is important to note that a number of factors often lie behind decisions to migrate). Furthermore, the women interviewed differ in regard to their migration status, which has implications for their class trajectories and narrations. All the interviews were undertaken in the southern part of the UK, mostly in London and Oxford.

\section{Social class and international migration}

Social class has formed an important part of some migration literature. Notably, scholars studying the incorporation of migrant workers in Western European labour markets in the post-war period considered how migrants fit into wider class structures and how their presence challenged traditional class concepts and categories (e.g. Castles and Kosack 1973, Castles et al. 1984, Miles 1982, Phizacklea and Miles 1980). Castles and Kosack (1973) conceptualised the participation of migrant workers in the post-war European workforce in terms of a 'reserve army of labour', particularly exposed to the instabilities and insecurities involved in capitalist 
economic cycles, while Miles (1982) used the concept of a 'racialised class fraction' to make sense of migrant workers' position in the wider working class.

Migration scholars have also considered ways in which class provides or restricts access to mobility, both in terms of how different resources can help facilitate migration, and in terms of the extent to which migration policies are shaped in favour of certain educational and professional profiles. In regards to resources, migrants holding economic, cultural and/or social capital have been found to have greater access to mobility than those with fewer resources (van Hear 2004, 2014). When it comes to migration policies, these have increasingly come to be tailored to encourage the migration of groups seen as economically beneficial to receiving countries, while aiming to block the entry and settlement of others. This includes the UK's 'managed migration' approach, which has implied a range of selective policies, with classed, gendered and racialized effects (Kofman and Raghuram 2006, 2015, Ruhs and Anderson 2010, Wills et al. 2009). Yet another link between class and migration noted in the literature relates to how class may form a motivating factor behind migration, e.g. in cases where migration is seen as a means to achieve certain class aspirations (Batnitzky et al. 2008, Mapril 2014).

While the relationship of social class and international migration has hence been considered from different angles, there is more to learn about class processes taking place in the context of international migration, and how they are experienced and understood by migrants. Although the contributions noted at the beginning of this section have been important for conceptualising migrants' positions in class terms, they do not capture the heterogeneity of those positions, the importance of which has arguably increased following labour market transformations and a growing diversity in migrants' social and educational backgrounds (Batnitzky et al. 2008, Verwiebe et al. 2014). More broadly, class has generally been less of a focus in migration studies in recent years (van Hear 2014), a gap this paper aims to address.

It will do so by building on the work of scholars such as Parrenas $(2000,2015)$ and Kelly $(2007,2012)$ whose research has added important insights into the complexity of social class processes involved in migration. Firstly, Parrenas' (2000, 2015) work on migrant domestic workers points towards the contradictions involved in achieving 
an improved economic position while experiencing a decline in social status. It also explores the transnational dimensions of class relations by considering the position of Filipina domestic workers both in relation to the middle-class Western women they work for and the local women some of them subcontract their own domestic work to upon migration.

Secondly, Kelly's (2007, 2012, Kelly and Lusis 2006) work on Filipina migrants in Canada considers how those migrants are positioned in both the sending and receiving country context. While he notes an overall pattern of 'deprofessionalisation and deskilling' (2012: 166), Kelly finds that the migrants themselves evaluate their class positioning in more complex ways. He points towards a number of factors that impact on that evaluation, including a perception of a 'strong sense of (class) immobility' in Philippine society, the prospect of mobility over time, and over generations, and 'the extension of class identity from the individual to a wider familial network', which implies, on the one hand, that migrants may be differently positioned when considering assets held by their families, and, on the other, that while migrants may experience deskilling through migration, their families often achieve an improved economic position as a result of receiving remittances (ibid 170-171). Furthermore, considering how migrants are positioned beyond the labour market adds to the complexity of their evaluations. Firstly, the fact of living and working abroad may imply that 'migrants enjoy an elevated status that goes beyond financial rewards' in the Philippine context (ibid 175); secondly, the social class markers that may not be recognised in the Canadian labour market (e.g. professional qualifications) might still be acknowledged within the migrant community, and hence impact on the social status migrants hold therein.

Aside from literature on social class and international migration, the paper is also informed by wider sociological debates about class. In recent years, sociological research on class has increasingly come to consider the role of non-economic factors in the reproduction of class divisions, and the work of Bourdieu $(1984,1986,1992)$ has had an important influence here. Work associated with the 'cultural turn' in class studies has pointed towards the limits of Weberian and Marxist class schemes that had come to dominate the class debate in the discipline. In particular, it has been suggested that their quantitative approach and strong focus on occupation as the core 
indicator of class fails to account for a range of social and cultural practices through which classes maintain their boundaries, as well as the different ways in which class features in people's everyday lives (Atkinson 2015, Crompton 2008).

Bourdieu-inspired research on class has used concepts such as habitus, cultural capital and social capital to explore different practices and resources used by people of different social classes, in order to secure a position of advantage, or attempt to overcome disadvantage (e.g. Divine et al. 2005, Lawler 2005, Oliver and O'Reilly 2010, Savage et al. 2005, 2013). Amongst other things, different ways of interacting and communicating, and different tastes and consumption patterns have been incorporated into a theory of class that aims to capture, more fully, how class relations are structured, experienced and reproduced in contemporary society. Importantly, this research has highlighted the fact that the social practices concerned are not just different, but also differently valued, whereby they contribute not only to defining and maintaining boundaries around different class groupings, but also to positioning them differently in the social hierarchy (Bourdieu 1984, Skeggs 1997).

The idea that class divisions entail cultural as well as economic dimensions has had methodological implications (Bradley and Hebson 1999), and we have seen a growing body of qualitative research on class, exploring how class is subjectively experienced and interpreted. Here, the ways in which class features in people's understanding of themselves and their position in society is considered, and links between class imaginaries, actions and structures are emphasised (e.g. Skeggs 1997, Reay 1998, 2005). The importance of 'understanding class from the individual subjects themselves' (Kelly 2012: 155) has been emphasized by both Parrenas and Kelly in their studies of class in the context of international migration. Similarly, this paper provides a 'subject level of analysis' (Kelly 2012), and explores how class features in the narratives of female migrants, both explicitly and implicitly: that is, both by considering how the migrants speak about class on class-terms, and by analyzing different features of their accounts that refer, more broadly, to their socioeconomic position. This is not intended to juxtapose 'objective' and 'subjective' dimensions of class, but rather to enable an investigation of different aspects of class processes, and how they are connected, in complex ways. On the one hand, a certain class consciousness (understood here in a broader sense than the traditional Marxist 
definition, see Reay 2005) may in some cases correspond to class-based actions and class structures. On the other, arguments for the irrelevance of class may function to reproduce class inequalities through a denial of privilege, and the justification of inequalities that follows (Lawler 2005, Reay 1998, Walkerdine 2003). More broadly, a tendency for people to down-play class as a significant part of their identities has often been noted in qualitative research (Bottero 2004), while indirect references to class-based identifications, as well as judgements of 'other' classes, have also been found to be common (Oliver and O'Reilly 2010, Reay 1998).

In what follows, I present some of the interview findings and discuss how they can help us make sense of social class processes in the context of international migration. I start by providing an overview of the different class trajectories of the women interviewed, and then go on to look at how female migrants make sense of their trajectories. Here, a number of different understandings and evaluations of class are considered, ranging from accounts that put emphasis on the loss of socioeconomic position and/or social status following migration, to those that consider social mobility from a longer-term perspective and/or from the point of view of the wider family unit, emphasise other quality-of-life aspects, or challenge the social hierarchies associated with different positions. This is followed by a discussion of how class intersects with gender and ethnicity, and the transnational context in which those processes take place.

\section{Social class trajectories and 'contradictory class mobility'}

As discussed, international migration may involve upwards or downwards social mobility, and examples of both can be found within the sample I draw on here. On the one hand, we see female migrants who have experienced migration in terms of career development and an improved socioeconomic position. This has particularly been the case of women who are highly educated and who have been able to use their qualifications in the UK, but also some women who have taken advantage of educational opportunities available in the UK and drawn on those to improve their socioeconomic position. One example is Anastasia, who moved from Russia with the aim of pursuing her career abroad, first in Australia, then in the UK. Anastasia is an accountant and spoke of her move to the UK as a good 'stepping stone in my career'. When comparing Russia and the UK, she said she finds that the UK offers greater 
opportunities, while in Russia, her perception is that you may work hard but not necessarily be better off financially or make progress in your career.

On the other hand, many women interviewed have experienced a blocked career trajectory upon migration, and have suffered from downwards mobility as a result and, overall, this has been a more common trajectory within the sample. One example is Ana, from Ecuador, who, like Anastasia, is an accountant. Ana moved to the UK following the separation from her partner, with whom she has a daughter, and she suggested that she migrated because of the stigma attached to being a single mother in Ecuador. Ana migrated by herself, while her daughter, who was a year old at the time, stayed with her parents, but her daughter has since joined her in the UK, and Ana also has another daughter. Ana worked in a bank prior to migrating, but has mainly done low paid service sector jobs in the UK, and, at the time of the interview, she worked as a cleaning supervisor. Ana suggested that she wanted to find another job, but that it is difficult to find work outside the cleaning sector for Latin American women, especially when you have childcare responsibilities.

Aside from cases that can be considered in terms of upwards or downwards mobility more straightforwardly, the sample also includes a number of women whose trajectories are better captured through the concept of contradictory class mobility (Parrenas 2000, 2015). Alise, from Latvia, worked as a building engineer before migrating to the UK. Despite having a professional career, Alise found herself unable to make enough money to be able to pay for her son's university education, whereby she migrated with the aim of achieving an improved financial position. At the time of the interview, Alise was self-employed as a cleaner (she previously worked for an agency), and, when talking about her employment trajectory, she referred to her limited English language skills as an important factor. Another example of contradictory class mobility is Raluca, who used to work as a teacher in Romania, and who came to the UK as an au pair with the hope of making the money that would enable her to gain independence and be able to move out of her parents' home. Both Raluca and her fellow national Simona worked as live-out domestic cleaners at the time of the interviews. They both felt empowered by the improved financial position they were in since migrating, but at the same time displayed an ambivalent relationship to their trajectories, expressed perhaps particularly in relation to their 
experience of people 'back home' looking down on their choices, moving from a professional career in Romania to cleaning in the UK. Particularly Simona seemed affected by this experience, and struggled to come to terms with the fact that she used to be a 'key worker' for an IT company and was now cleaning and 'ironing boxers' for middle-class English people.

In the next part of the paper, I will consider different ways in which female migrants evaluate their social class trajectories. In particular, I will explore narratives that surround experiences of downwards and contradictory class mobility. Those narratives include accounts that emphasize the difficulties involved, but they also include a number of other evaluations, where focus is shifted towards other aspects of the migratory experience, or where a range of factors help to balance and/or mitigate the individual experience of downwards mobility.

\section{Narratives of downwards mobility}

This section looks at narratives that have highlighted difficulties associated with downwards mobility, and that point towards different mechanisms seen to pose obstacles for migrants. While the discussion is largely focused on the women's experiences in the UK, it also considers how migration has impacted on their positions in the sending country context.

\section{Financial difficulties, life-style changes, and a decline in social status}

Some of the women interviewed focused rather strongly on the experience of downwards mobility in their narratives. Reshmi, from India, compared her life and career in India with her situation in the UK at the time of the interview, and highlighted the implications the move had for her socioeconomic position and professional status. She migrated to the UK with her young son to join her husband, who had moved in order to study, and although the couple has since separated, Reshmi decided to stay so that her son would be able to see both his parents. Before she migrated, Reshmi worked as a manager for a multinational company. She described this as a 'very successful career', the job as 'very highly paid', and, more broadly, she talked about her situation in India as privileged. She contrasted this with her position in the UK, which she sees as disadvantaged. One example she 
highlighted is the fact that she and her son had to share rented accommodation with two other people due to the high costs.

A number of interviewees who have experienced downwards mobility have highlighted the financial implications of not being in work, doing low paid jobs, or being paid less than what is needed to maintain the desired life-style. Jasmin, from Kashmir, who was unemployed at the time of the interview, said that although she and her husband manage financially, there are a number of things you cannot do unless both spouses work. The effects of low paid work was highlighted by Polish woman Klara, who suggested that finding a 'proper job' is crucial for being able to 'feel independent', have a social life, and do things like go on holiday. Like Reshmi, Klara is a single parent, which has additional implications for her financial position.

Aside from the financial implications of downwards mobility, a number of interviewees also highlighted the question of social status. Adanna from Zimbabwe migrated on a student visa in order to undertake postgraduate studies, but struggled to complete her course because of childcare responsibilities. This meant that she had to stay in the UK in order to complete her studies and pay off her student debts. At the time of the interview, Adanna worked as a care worker, beneath her level of qualification, with low pay and unstable work conditions, which implied a difficult financial situation. She suggested that she had applied for jobs that required higher skills, but had been unable to get those despite her qualifications. Adanna did not want to refer to the work she did at the time of the interview as her job, because she felt that it did not represent her, indicating a wish to uphold a social status associated with her qualifications rather than her job and labour market position.

\section{Accounts of discrimination and disadvantage}

Some of the women who have emphasised difficulties associated with the experience of downwards mobility have highlighted factors they think have functioned to discriminate against them in the UK. Some found themselves unable to get shortlisted despite being well qualified for professional jobs. Others were invited to interviews, but not getting the jobs. Reshmi mentioned that she frequently received good feedback following an interview, but was told that the job in question was given to a person who had 'done a similar job before', which made her feel as though she was 
rejected due to being a migrant. Another interviewee who expressed a sense of disadvantage is Klara, who has a postgraduate degree in Economics, and a range of professional experiences in marketing, sales and production, but struggled to find work corresponding to her qualifications in the UK. At the time of the interview, Klara worked on a project for her local council, but was on a fixed-term contract and a low wage, which meant that she needed to supplement her job with part-time care work. By contrast to Alise, who suggested that her limited English language skills had been an obstacle for pursuing a professional career, Klara's English language skills are good, and she instead pointed towards discrimination, noting that she was employed at a lower level than graduates without work experience: 'You know, it's not nice when a graduate without experience is paid much better than I am paid. Is it fair? I don't think so'.

In terms of the discriminatory mechanisms involved, the racialization of different migrant groups has often been highlighted as an obstacle for achieving a good position in the UK labour market. Adanna spoke of stereotypes of African migrants, suggesting that Africans are perceived as cheap labourers, suitable for low paid jobs, while Klara pointed towards negative images of Polish migrants in the UK, centered on the competition those workers are seen offer to the local workforce. Raluca also mentioned negative representations of Eastern Europeans, and said that many Romanians feel that people judge them. She made reference to stereotypes of Eastern European migrants doing low-skilled work in the UK, and said, 'I have complexes about being Romanian, and when they ask me what I do and I say I am like a cleaner, and it's like a cliché, all Eastern Europeans are cleaners' (on the racialization of Eastern European migrants in the UK, see Fox et al. 2012, 2015).

For some interviewees, informal forms of discrimination are accompanied by restrictions to do with their migration status, which further adds to the obstacles they encounter in the labour market. This was the case for Adanna, who arrived on a student visa, but whose migration status changed after she completed her studies. At the time of the interview, she did not have a work permit, which significantly impacted on her employment options. Another interviewee who highlighted problems associated with migration status is Jasmine, who initially moved to the UK in order to pursue a postgraduate degree and stayed after she met her husband, who is from 
Mauritius and works as a nurse. Being on a dependent visa has meant that Jasmine has not been able to get financial support when unemployed, access training, or get help with finding suitable employment.

While most of the women interviewed had legal status in the UK at the time of the interviews, some of those who did not emphasised the stress and insecurity involved. Furthermore, many of those who had legal status were on time-limited and/or dependent residence permits. While a detailed exploration of the impact of migration status on individual trajectories is beyond the scope of this paper, it is important to note, firstly, that the limits implied by an irregular status, but also different forms of restricted residence permits, have significant implications for migrants' job opportunities. Secondly, experiencing an insecure migration status is likely to impact on migrants' evaluation of their class trajectories, in the sense that legal status may form a more immediate concern than the broader question of downwards mobility (Anthias et al. 2013). It should be emphasised here that the selective migration policies discussed earlier have gendered effects, in terms of migrants' access to mobility, and access to rights (Kofman 2007, Kofman and Raghuram 2006, 2015).

\section{Downwards mobility and the sending country context}

While most of the narratives centred on the experience of downwards mobility focus on factors associated with the UK, some accounts have also highlighted negative perceptions of migrants in the sending country context. These were mentioned in particular by a number of Eastern European women, including Simona, whose ambivalent evaluation of her class trajectory was discussed earlier, partly with reference to people 'back home' looking down on her move from a professional career to a low status job. Klara recounts a similar experience, and noted that she often reads negative representations of migrants in the Polish media: 'opinions are so low about Polish migrants who come over here because of articles on the website or in Polish press is very negative ... people read such articles in press or on website and say "what are you doing there in the UK?" ... "you are highly educated" ... Of course I want to find a job that will give me fulfilment or satisfaction ... but I couldn't find such a job in Poland and here I have a chance'.

The representations referred to appear to be rather centred on the low social status 
held by some migrants in the UK, and their impact on public perceptions contribute not only to how migrants evaluate their class trajectories, but also to how they relate to the sending country context. Speaking of friends in Romania who have managed to get ahead, get married and buy a flat, Raluca said that while she keeps in touch with people, 'there are some things I can't talk to them about', and this revolves around her work situation: 'they ask me what I am doing and I say I am still cleaning and they say “oh, you are losing yourself", and I don't feel as communicative as I used to be about that, because it's like every time you talk to them you have to justify yourself, and I don't have to justify'. In other words, Raluca's engagement with people in her home country are limited due to lack of understanding and acceptance of her position in the UK. This represents an important difference from Kelly's (2012: 175) finding that the experience of an 'elevated status' in the sending country was often enjoyed by migrants. By contrast, the findings presented here suggest that for some migrants, the experience of downwards mobility impacts on their social status in both the sending and receiving country.

\section{Alternative evaluations of downwards mobility}

So far, I have focused on evaluations of class trajectories that emphasise difficulties associated with downwards mobility. In what follows, I will consider alternative evaluations of downwards mobility, including narratives where class trajectories are considered from a longer-term perspective, and in relation to the wider family unit; accounts emphasising the importance of family life, and those that reflect on differences in gender arrangements in different country contexts; and efforts to rethink the meanings associated with different kinds of work and class hierarchies.

\section{A longer-term perspective on class, set in a family-wide context}

One way in which the female migrants interviewed have talked about the experience of downwards mobility has been by considering the process of social mobility from a longer-term perspective. As we saw from the earlier quote, Klara noted obstacles, but at the same time seemed determined to achieve an improved position over time - and while finding herself in a difficult situation at the time of the interview, she expressed hopes for her future career prospects in the UK. Similar accounts have come from other interviewees, who have emphasised the opportunities they associate with the UK. Ryan's recent (2015) work on Polish migrants in the UK shows that migrants 
may experience an initial deskilling that is then followed by upwards mobility, suggesting that time is an important factor (see also Eade 2007, Nowicka 2013, 2014). It is also worth considering the fact that the accumulation of non-economic resources or forms of capital may form part of a longer-term class strategy (Eade 2007, Nowicka 2013, 2014), and that migrants are involved in the reproduction of class not only through their role as workers, but also in their roles within the family (Kofman and Raghuram 2015). For instance, Lopez Rodriguez' (2010: 340) research on Polish mothers in the UK pointed towards 'an almost 'middle class' involvement in their children's education' amongst mothers of different class positions, highlighting the fact that class practices may vary across different social arenas.

In addition to the partial acceptance of a period of downwards mobility in light of the hope that greater opportunities will emerge over time, Klara also highlighted familyrelated factors as impacting on the decision to migrate, and said that 'the reason I decided to come over was to make a better life for me and for my son'. While her son found the move to the UK difficult to some extent, Klara suggested that he saw the advantages the move would bring, in terms of improved opportunities. Emphasis on the opportunities gained by children through migration was seen also in the narrative of Alise, from whom a key motivating factor behind her migration was the ability to pay for her son's university education. Lopez Rodriguez' (2010) research on Polish mothers similarly suggests that children's opportunities are important motivations for (female) migrants. Furthermore, the prospect of upwards mobility for migrants' children can help mitigate the experience of downwards mobility for the migrants themselves, confirming the importance of taking a family-wide and inter-generational perspective on social mobility (Kelly 2007, 2012, Nowicka 2013, 2014). While not directly related to class aspirations as such, another example of how a consideration of the children's experiences has impacted on migratory decisions was seen in the case of Reshmi, for whom her son's ability to see both his parents formed an important reason for staying in the UK.

Another way in which migration has been considered in the context of the family concerns cases where migrants help support their families through remittances. This was mentioned by a number of women, including Simona, who, together with her two older sisters (who are both domestic workers in Italy), sends money to her parents in 
Romania. It is also worth highlighting the fact that in some cases, the family has helped, financially, to mitigate the experience of downwards mobility. Ester, from Venezuela, had a high-powered job in a government organisation before migrating to the UK for post-graduate study. Having met her husband in the UK, Ester stayed after completing her studies, but was unable to find work in line with her previous career. Aside from the implications this had on her professional status, it also meant that she became financially dependent upon her husband. While that undoubtedly helped mitigate the impact of downwards mobility, it is noteworthy that Ester presents this less in terms of financial security and more in terms of the lack of independence implied, which she found difficult to deal with.

The importance of family life, and some reflections on different gender arrangements Another way in which women have talked about the experience of downwards or contradictory mobility has been through emphasising quality-of-life aspects other than those associated with careers and socioeconomic positions. Nowicka's (2014) research on Polish migrants in the UK found that narratives around 'success' often shifted to experiences other than those relating to employment: presenting migration as part of a process of 'personal maturation', or emphasising the importance of family life and the opportunities gained by children, amongst other things. The importance of family life was also discussed by several women in the sample I draw on here. Ester, whose professional career was disrupted through migration, noted that migration has enabled her to achieve quality in other aspects of her life, by meeting her husband and creating a family, something she felt unable to do before - partly because of the demands of her job, but also because of how she perceives of the gender roles and expectations that are embedded in relationships with men in her home country. Another interviewee who emphasised the importance of family life is Jasmine, who, like Ester, has struggled to find a professional job in the UK, and who spoke extensively about making efforts to pursue her career ambitions in the community and voluntary sector. At the same time, Jasmine noted that her priorities have changed significantly since having a child, and she generally emphasised the fact that she is happy with her life in the UK. As such, we see that both Ester and Jasmine emphasise the happiness they have gained in their personal life following migration, through creating a family, which comes across as an important quality-of-life aspect. 
While for a number of women interviewed, meeting their partner and creating a family appears to simply have happened in the UK, some have emphasised perceived cultural differences as a contributing factor. As just noted, Ester suggested that traditional gender arrangements, and the expectations involved, was one of the reasons she was single prior to migrating, whereas her view and experience of intimate relations in the UK is rather different. More broadly, constraints relating to traditional gender roles and relations in the sending country context were highlighted by a number of interviewees, including Reshmi, who suggested that she has been able to pursue a number of personal interests since migrating to the UK (such as learning to swim, cycle and drive a car), whereas she thinks that the strong focus put on family life in her culture means that women sometimes do not prioritise time to themselves.

In addition, we have seen that concerns for the well-being of, and increased opportunities for, their children have been important motivating factors behind migration for a number of women. However, it is worth noting that in some cases where women emphasise family-related aspects of their lives, they also reflect upon the impact their socioeconomic position has on their ability to structure their family life in the desired manner. One issue relates to work life/family life balance, and concerns the time the women spend doing paid work, something that Klara highlighted in relation to needing to combine two jobs and work at the weekend. More broadly, Ana talked about the difficulty of achieving a good balance between work and home life, and bringing up her daughters successfully whilst feeling more of a part of British society herself. She explained that her job does not help her integrate (partly due to the fact that many of her co-workers are also migrants), and found it frustrating not to be able to find work enabling her to do so. While Ana did not expand further on the effects this has on her family, it seems possible that her inability to find a job with more potential for integrating into society also has implications for her children's experience. In addition, it is worth noting that while Ana emphasised the opportunities she associates with the UK (which she contrasted to her home country), her narrative indicates that she has had limited access to those opportunities as a migrant.

Re-thinking the meanings of different kinds of work, and social class hierarchies 
Yet another way in which the female migrants interviewed have made sense of and talked about the experience of downwards mobility has been to re-think the meanings associated with different kinds of work, as well as the social class hierarchies that are connected to them. While, as we have seen, many women in the sample have been unable to find employment corresponding to their educational and professional backgrounds, some of them have nonetheless recounted fulfilling work experiences, and these appear, to some extent, to make up for the downwards mobility experienced. At the time of the interview, Ester worked for an organisation that supports disadvantaged migrants, which she suggested made her feel 'useful', and as if she was 'doing something important'. Similarly, Reshmi's account of her previous job for a small voluntary organisation highlighted the important aspects of that work, along with the relationships she established through it - and, in relation to that, Reshmi spoke about the benefits involved in transgressing social class boundaries. While most of her social networks in India involved people who shared her class position, in the UK, she has created friendships with people with whom she shares what she talks about in terms of 'commonalities' (interests and experiences), and who are not just 'socially fit' (i.e. seen as suitable friends because of a shared social/class position), something she has found enriching. Another example comes from Raluca, who suggested that it is good for highly educated people to work with less educated people, in order to broaden their experiences and learn about the perspective of those from another social background.

In terms of the meanings attached to 'un-skilled' jobs, one interviewee who reflected on this issue is Ana, who appeared to reconcile the downwards mobility she has experienced partly by emphasising that cleaning is something that everyone does. A particularly interesting account of this was provided by Raluca, who emphasised the importance of engaging in 'material' chores, and went on to construct an empowered and class-conscious identity in opposition to what is looked down upon amongst middle-class people. Notably, she suggested that Romanians find it 'sad' that rich people do not engage in 'practical' things, but get others to do everything for them. The implication here is that some (British) people miss out on life experiences because of their class position and reluctance to engage in manual labour, while others (Romanians) understand the value of this work for their well-being: 'for Romanians ... (i)ts like, it's a bit sad, you know, not work and get people to do your 
house' (the particular reference here being to housewives who employ domestic workers). Aside from constructing a particular class position, this part of Raluca's narrative also ties into the production of a particular ethnic identity. She related the focus she suggested Romanians have on making money and achieving a better social position to the history of Romania and the instabilities people have faced after communism. Particularly when she spoke about the stress her mother experienced, Raluca expressed some dislike for British people, suggesting that things are easy for them because they happen to be born in a rich country. Aside from how class informs Raluca's construction of a Romanian identity here, it is also central to her perception of British-ness, in relation to which her experience of a specific social class is used to generalise about a wider national/ethnic group.

\section{Differences in narratives of social class trajectories}

In these two sections, we have seen a number of different ways in which downwards/contradictory class mobility is made sense of by the female migrants interviewed. These have included narratives that are focused on the experience of downwards mobility, but they also include accounts that conceive of migration from a longer-term perspective, and in the context of the family unit; that emphasize other quality-of-life aspects, such as family life; and that challenge the meanings associated with different kinds of work, while re-thinking social class hierarchies ${ }^{1}$. More broadly, what these findings tell us is that socioeconomic trajectories are experienced and interpreted by female migrants in different ways. As such, they point towards the importance of considering subjective understandings of class processes, and the fact that evaluations of class-related experiences depend on a range of factors. The biographical approach is well suited for this, and enables us to situate social class trajectories in wider biographical narratives. It also helps us to explore different dimensions of class, including the class structures in which migrants are positioned, the different social, cultural and symbolic processes whereby class relations are reproduced, and the extent to which class features in the migrants' understanding of their experiences.

\footnotetext{
${ }^{1}$ It is important to note here that interviewees may be concerned to present themselves in particular ways, and that the denial of discrimination or disadvantage may in some cases form part of a claim to a particular position in the social hierarchy (Cederberg 2014, Fox et al. 2015).
} 


\section{Class, gender and ethnic processes in a transnational context}

While focused on class in particular, the discussion has also highlighted a number of ways in which class trajectories intersect with structures and processes related to gender, 'race', ethnicity and nationality. In regards to gender, female migrants' position in the family, community and wider society is in multiple ways shaped by gendered structures and processes: from unequal divisions of domestic labour and care responsibilities, which impact on the women's ability to engage in other activities, through labour market inequalities that shape women's employment incorporation, to traditional gendered ideologies that condition women's engagement in different areas of social life (Morokvasic 1984, Kofman 1999, Kofman et al. 2000, Kofman and Raghuram 2015). In some cases, gendered experiences have functioned as 'push' factors for migration, as women have moved in order to try and escape gender arrangements that were perceived as constraining or oppressive. While a number of those women have found the UK to offer greater possibilities, gendered processes have contributed to the position of the female migrants interviewed also in the UK. On the one hand, many of them work in feminised sectors of the labour market, including care work, and a range of service sector jobs. On the other, childcare responsibilities, limited access to childcare (both due to the costs involved, and because migration has implied less access to informal help, e.g. from family members), and, in some cases, an unequal division of domestic and care work in families, have been emphasised in several narratives. Furthermore, as noted previously, the effects of migration policies are gendered, which shapes the experience of migration in a number of different ways. In turn, these factors impact on women's class positions, in terms of their financial position, life-style and social status.

Class also intersects with processes and structures relating to 'race', ethnicity and nationality in a number of ways. These include the racialization of different migrant groups (which in the examples discussed notably involved class-based stereotypes), which contribute to their labour market opportunities. They also include the fact that nationality (along with educational and professional profiles) impact on migrants' legal status in the UK, with a range of implications, as discussed earlier. In addition, a factor that has been briefly referred to but not explored in any detail concerns the ethnicisation of particular labour market sectors, which contributes to migrants' 
opportunities for intra- and inter-ethnic engagement. Yet another way in which class relates to ethnic processes concerns the extent to which the experience of downwards mobility impacts on how migrants relate to different social contexts, and some of the women interviewed highlighted how blocked social mobility impacted on their ability to develop a sense of belonging to the receiving society (see Anthias et al. 2013 for further discussion about the relationship between employment and social integration).

Having pointed towards some of the ways in which class intersects with other social processes and divisions, I will briefly highlight the importance of considering the transnational context in which those processes take place. As we have seen, the female migrants interviewed as part of this research talk about their class trajectories with reference to factors in sending as well as receiving country contexts, and, in some cases, by considering their social position in both locations simultaneously. As such, not only their employment and social incorporation in the UK, but also their relations with, and connections to, families and wider communities in the sending country impact on how female migrants evaluate their social class trajectories, and, more broadly, the experience of migration. Furthermore, a transnational frame of reference has in many ways shaped the narratives of the female migrants interviewed, as their perceptions of opportunities and constraints in the sending and receiving country respectively feature in their migratory decisions, evaluations of migration, and future plans. As such, the findings confirm the importance of developing a transnational framework for understanding class processes (Eade 2007, Kelly 2012, Nowicka 2013, 2014).

\section{Conclusion}

This paper has conveyed some of the complexity that surrounds social class processes taking place in the context of international migration. Firstly, we have seen that migration can involve upwards or downwards mobility, that migrants can experience both at the same time, and that time is an important factor to consider, as upwards mobility may follow initial de-skilling. Secondly, we have seen that migrants make sense of and evaluate class trajectories in different ways. While some accounts put focus on the difficulties associated with downwards mobility, we also see those that emphasise other quality-of-life aspects, such as family life; focus on the opportunities gained for the children and wider family through migration; and highlight the 
enriching aspects of performing different kinds of work and transgressing class boundaries, while challenging the meanings associated with class hierarchies. Such findings confirm the importance of considering class processes taking place through migration from the perspective of individual migrants, of exploring how class relates to other factors and experiences, and of viewing class in terms of a process.

While social mobility has often been considered in the migration literature, the implications for migrants' class positioning has been less of a focus, and a key aim of this paper has been to address this gap. This means attending to both the socioeconomic trajectories of migrants and the wider economic structures and social hierarchies in which they are embedded. Importantly, class relations are reproduced symbolically as well as economically, and, as we have seen, the narratives analysed in the paper have frequently emphasised not only economic advantages and disadvantages, but also the question of social status. A conceptualisation of class that takes account of different aspects of class is therefore important.

Building on the work of Parrenas (2000, 2015) and Kelly (2007, 2012, Kelly and Lusis 2006), this paper contributes to our understanding of class in a migration context by considering the diverse ways in which class is experienced and narrated by female migrants. While some findings correspond to those of Kelly's research, the narratives presented here highlight additional ways of understanding class trajectories, and I would like to emphasise two key points. The first concerns the intersection of class and gender, and the second relates to the re-thinking of social class hierarchies.

In regards to the first point, we have seen that it is important to consider evaluations of class in relation to other aspects of the migratory experience, and, in particular, the intersection of class and gender has been highlighted in the paper. The narratives presented have pointed towards a number of ways in which gender has impacted on the female migrants' socioeconomic position and trajectory; furthermore, accounts of gender in/equality have been central to many narratives, and have impacted on how the women evaluate class-related aspects of their experiences (e.g. in cases where perceptions of gendered emancipation appear to mitigate the experience of downwards class mobility). It is worth noting here that intersectional approaches have become increasingly popular for understanding a range of social phenomena, 
including migration (for a recent overview, see Kofman and Raghuram 2015). While emphasising (and illustrating) the importance of considering how different social processes intersect to shape particular experiences and positions, this paper has foregrounded class, which, despite being frequently noted in the literature on intersectionality, has been less of a focus of analysis than gender, 'race' and ethnicity (Anthias 2013, Kofman and Raghuram 2015), and hence merits further study.

In terms of the second point, we have seen that migrants at times re-think and reformulate social class hierarchies, by challenging dominant meanings associated with different positions, or by emphasising the advantages of transgressing class boundaries. This puts focus on the social meanings that are attached to class hierarchies, but also highlights the fact that those meanings are not fixed - and narratives providing an alternative reading of social hierarchies could be seen to offer a form of political challenge, e.g. by questioning dominant valuations of different skills and roles. However, as noted earlier, class imaginaries and structures are related in complex ways, and such re-formulations could also be seen to play a reproductive function, insofar as they may imply that people stay in their class position, rather than contribute to the transformation of class structures. Whatever the function may be, the narratives generally illustrate the importance of an approach to class that provides insight into the different levels at which class relations are shaped and reproduced, as well as how class is experienced. As noted above, class relations, identities and processes are complex when considered in the context of international migration (which is not to suggest that class is not complex, and at times contradictory, in other social contexts). As I have shown in the paper, migrants' narratives of class provide useful insights into that complexity, and therefore help advance our understanding of class and migration.

\section{Funding statement}

This work was supported by the 6th Framework Programme of the European Commission Scientific Support to Policies SSP4 (Contract Number 022666).

\section{Acknowledgements}

The narratives drawn on here were undertaken as part of the research project FeMiPol: Integration of female immigrants into labour market and society, directed 
by Professor Floya Anthias. I would like to thank the other researchers involved in the UK project team, Floya Anthias, Ron Ayres and Tamsin Barber. I would also like to thank Bryan Mabee, Maria Villares-Varela and two anonymous reviewers for useful comments on earlier drafts of the paper.

\section{References}

Anthias, F. et al. (eds.) 2013. Paradoxes of Integration: Female Migrants in Europe. Springer Verlag.

Anthias, F. 2013. 'Intersectional what? Social divisions, intersectionality and levels of analysis.' Ethnicities 13(1): 3-19.

Atkinson, W. 2015. Class. Cambridge: Polity Press.

Batnitzky, A. et al. 2008. 'A middle-class global mobility? The working lives of Indian men in a west London hotel.' Global Networks 1: 51-70.

Batnitzky, A. et al. 2009. 'Flexible and Strategic Masculinites: The Working Lives and Gendered Identities of Male Migrants in London.' Journal of Ethnic and Migration Studies 35(8): 1275-1293.

Bottero, W. 2004. 'Class Identity and the Identity of Class.' Sociology 38(5): 9851003.

Bourdieu, P. 1984. Distinction: A Social Critique of the Judgement of Taste. London: Routledge \& Kegan Paul.

Bourdieu, P. 1986. 'The forms of capital.' In Richardson, J. (ed.) Handbook of Theory and Research for the Sociology of Education. New York: Greenwood Press, 241-258.

Bourdieu, P. and Wacquant, L. 1992. An Invitation to Reflexive Sociology. Cambridge: Polity Press. 
Bradley, H. 2014. 'Class Descriptors or Class Relations? Thoughts Towards a Critique of Savage et al.' Sociology 48(3): 429-436.

Bradley, H. and Hebson, G. 1999. 'Breaking the silence: the need to re-articular “class".' International Journal of Sociology and Social Policy 19(9/10/11): 178-203.

Castles, S. and Kosack, G. 1973. Immigrant Workers and the Class Structure of Western Europe. London: Oxford University Press.

Castles, S. et al. 1984. Here for good: Western Europe's new ethnic minorities. London: Pluto Press.

Cederberg, M. 2014. 'Public Discourse and Migrant Narratives of Integration and Inequality: Language and Power in Biographical Narratives', Sociology, 48(1): 133149.

Crompton, R. 2008. Class \& Stratification. $3^{\text {rd }}$ ed. Cambridge: Polity Press.

Devine, F. et al. (eds.) 2005. Rethinking class: Culture, identities and lifestyle. Basingstoke: Palgrave Macmillan.

Eade, J. 2007. Class and Ethnicity: Polish Migrant Works in London: Full Research Report. ESRC End of Award Report, RES-000-22-1294. Swindon: ESRC.

Fox, J. et al. 2012. 'The Racialization of the New European Migration to the UK.' Sociology 46(4): 680-695.

Fox, J. et al. 2015. 'Denying Discrimination: Status, 'Race', and the Whitening of Britain's New Europeans.' Journal of Ethnic and Migration Studies 41(5): 729-748.

Glick-Schiller, N. et al. 1992. 'Transnationalism: A New Analytic Framework for Understanding Migration.' Annals of the New York Academy of Sciences, 645: 1-24. 
Kelly, P. 2007. 'Filipino Migration, Transnationalism and Class Identity.' Working Paper Series No. 90. Asia Research Institute, National University of Singapore.

Kelly, P. 2012. 'Migration, Transnationalism and the Spaces of Class Identity.' Philippine Studies: Historical and Ethnographic Viewpoints, 60(4).

Kelly, P. and Lusis, T. 2006. 'Migration and the transnational habitus: Evidence from Canada and the Philippines.' Environment and Planning, 38: 831-847.

Kofman, E. 1999. 'Female 'birds of passage' a decade later: Gender and immigration in the European Union.' International Migration Review 33(2): 269- 299.

Kofman, E. 2007. 'The knowledge economy, gender and stratified migrations.' Studies in Social Justice 1(2): 122-135.

Kofman, E. et al. 2000. Gender and International Migration in Europe. Employment, welfare and politics. London: Routledge.

Kofman, E. and Raghuram, P. 2006. 'Gender and global labour migrations: Incorporating skilled workers.' Antipode 38(2): 282-303.

Kofman, E. and Raghuram, P. 2015. Gendered Migrations and Global Social Reproduction. Basingstoke: Palgrave Macmillan.

Lawler, S. 2005. 'Introduction: Class, Culture and Identity.' Sociology 39(5): 797806.

Lopez Rodriguez, M. 2010. 'Migration and a quest for 'normalcy'. Polish migrant mothers and the capitalization of meritocratic opportunities in the UK.' Social Identities 16(3): 339-358.

Mapril, J. 2014. 'The Dreams of Middle Class: Consumption, Life-course and Migration Between Bangladesh and Portugal.' Modern Asian Studies 48(3): 693-719. 
Miles, R. 1982. Racism and migrant labour. London: Routledge.

Morokvasic, M. 1984. 'Birds of passage are also women.' International Labour Review 18(4): 886-907.

Nowicka, M. 2013. 'Positioning Strategies of Polish Entrepreneurs in Germany: Transnationalizing Bourdieu's Notion of Capital.' International Sociology 28(1): 2947.

Nowicka, M. 2014. 'Successful Earners and Failing Others. Transnational Orientation as Biographical Resource in the Context of Labor Migration.' International Migration 52(1): 74-86.

Oliver, C. and O’Reilly, K. 2010. 'A Bourdieusian Analysis of Class and Migration: Habitus and the Individualizing Process.' Sociology 44(1): 49-66.

Parrenas, R. 2000. 'Migrant Filipina Domestic Workers and the International Division of Reproductive Labour.' Gender and Society 14(4): 560-580.

Parrenas, R. 2015. Servants of Globalization. $2^{\text {nd }}$ ed. Berkley, CA: University of Stanford Press.

Phizacklea, A. and Miles, R. 1980. Labour and Racism. London: Routledge.

Portes, A. et al. 1999. 'The Study of Transnationalism: Promises and Pitfalls of an Emergent Research Field.' Ethnic and Racial Studies 22(2): 217-237.

Reay, D. 1998. 'Rethinking Social Class: Qualitative Perspectives on Class and Gender.' Sociology 32(2): 259-275.

Reay, D. 2005. 'Beyond Consciousness? The Psychic Landscape of Social Class.' Sociology 39(5): 911-928. 
Ruhs, M. and Anderson, B. (eds.) 2010. Who Needs Migrant Workers? Labour Shortages, Immigration, and Public Policy. Oxford: Oxford University Press.

Ryan, L. 2015. 'Another year and another year': Polish migrants in London extending the stay over time. Summary Report. Social Policy Research Centre, Middlesex University, London.

Savage, M. et al. 2005. 'Capitals, assets, and resources: some critical issues.' The British Journal of Sociology 56: 31-47.

Savage M. et al. 2013. 'A new model of social class? Findings from the BBC's Great British Class Survey experiment.' Sociology 47(2): 219-50.

Skeggs, B. 1997. Formations of Class and Gender. London: Sage.

Van Hear, N. 2004. 'I went as far as my money would take me': conflict, forced migration and class.' COMPAS Working Paper No. 6. University of Oxford.

Van Hear, N. 2014. 'Reconsidering Migration and Class.' International Migration Review 48(1): 100-121.

Verwiebe, R. et al. 2013. 'New forms of intra-European migration, labour market dynamics and social integration in Europe.' Migration Letters 11(2): 125-136.

Walkerdine, V. 2003. 'Reclassifying upward mobility: Femininity and the neo-liberal subject.' Gender and Education 15(3): 237-48.

Wills, J. et al. 2009. Global Cities at Work. New Migrant Divisions of Labour. London: Pluto Press. 